\title{
Antiviral Phytomedicine Elderberry (Sambucus) in China
}

\author{
Frank $\mathrm{Fu}^{1}$, Mingshu $\mathrm{Xu}^{2}$, and Weidong $\mathrm{Li}^{1}$ \\ ${ }^{1}$ Beijing University of Chinese Medicine \\ ${ }^{2}$ Natural Medicine, Horticulture Institute of New Zealand
}

June 3, 2021

\begin{abstract}
There is no specific medicine recommended during the emergency of 2019-nCov has been an outbreak and in COVID-19 outbreak zone where the climate is mildly warm, we highly recommend to use the elderberry in order to protect your health and there are 2 species of elderberries: one, Sambucus adnata, is termed the "blood-red herb-elderberry" by local residents as the roots, rhizomes, and branches exude red-juice when broken; the second, named S. javanica or S. chinensis is commonly called the "herb-elderberry". This therapeutics paper aims to publish our monography on the elderberry, as no English literature references are present in China because most Chinese horticulturists and farmers consider the elderberry a wild plant. It is regarded as a plant of little value due to its abundance and ease of harvest. Our article contains details of the Sambucus species groups, including the botanical names, Chinese common names, geographic distributions, medical uses.
\end{abstract}

\section{INTRODUCTION}

On the 31st December, 2019, the WHO China Country Office was informed of the cases about the pneumonia of unknown microbial aetiology associated with Wuhan City, Hubei Province, China. ${ }^{1}$ WHO has named the "coronavirus disease 2019" short for COVID-19. ${ }^{2}$ Seasonal outbreaks of the virus affect nearly $10 \%$ of the world population and may lead up to a million deaths annually. ${ }^{3} \mathrm{WHO}$ announcements there is no specific medicine recommended to prevent or treat the new coronavirus COVID-19. Although the specific medicines are not effective against COVID-19, all specific medicines against respiratory illnesses are highly recommended to protect your health. ${ }^{4}$

The outbreak of COVID-19 worldwide and over centuries history of antimalarials remind us there are many important medicinal values drugs and currently used antimalarial drugs are derived from plants. Artemisinin from the Qinghao plant (Artemisia annua L, China, 4th century) and quinine from the cinchona tree (South America, 17th century $)^{5}$.

The name atropine was coined in the 19th century, when pure extracts from the belladonna plant Atropa belladonna were first made ${ }^{6}$. Berberine is a compound found in several different plants, including Barberry (Berberis vulgaris), Oregon Grape (Mahonia aquifolium), Goldenseal (Hydrastis canadensis), and Chinese goldthread (Coptis chinensis). It has a 3000-year history of use in traditional Chinese and Indian medicine ${ }^{7}$. Reserpine was isolated in 1952 from the dried root of Rauvolfia serpentina (Indian snakeroot) ${ }^{8}$. Tubocurarine is a naturally occurring mono-quaternary alkaloid obtained from the bark of the Menispermaceous South American plant Chondrodendron tomentosum, and it contains highly toxic alkaloids and is one of the sources of the arrow poison curare ${ }^{9}$. Papaver somniferum, commonly known as the opium poppy or breadseed poppy is a species of flowering plant in the family Papaveraceae ${ }^{10}$. "Breadseed or opium poppy, Papaver somniferum". University of Wisconsin Extension, Master Gardener Program. Retrieved 7 January 2018 ${ }^{11}{ }^{12}$.

Ephedra sinica (also known as Chinese ephedra or Ma Huang) is a plant species native to Mongolia, Russia (Buryatiya, Chita, Primorye), and northeastern China (Gansu, Hebei, Heilongjiang, Jilin, Liaoning, Nei 
Mongol, Ningxia, Shaanxi, Shanxi ${ }^{13}$. Paclitaxel was isolated from the bark of the Pacific yew, Taxus brevifolia, hence its name "taxol" Paclitaxel (PTX), sold under the brand name Taxol among others, is a chemotherapy medication used to treat a number of types of cancer. This includes ovarian cancer, breast cancer, lung cancer, Kaposi sarcoma, cervical cancer, and pancreatic cancer ${ }^{14}$. Camptothecin (CPT) is a topoisomerase inhibitor. It was isolated from the bark and stem of Camptotheca acuminata (Camptotheca, Happy tree), a tree native to China used as a cancer treatment in Traditional Chinese Medicine.The stem bark of Mappia foetida, a tree native to India, has proved to be another source significant for the isolation of camptothecin ${ }^{15.16}$. Maitansine (INN), or maytansine (USAN), is a cytotoxic agent. It inhibits the assembly of microtubules by binding to tubulin at the rhizoxin binding site. It is a macrolide of the ansamycin type and can be isolated from plants of the genus Maytenus ${ }^{17}$.

For more than 50 years, low-cost antimalarial drugs silently saved millions of lives and cured billions of debilitating infections. Although effective new drugs are available, they are unaffordable for the majority of the affected population, even at a cost of one dollar per course. ${ }^{5}$ In 2002 , WHO published a monograph which stated the use of elder flower herbal preparation "as an expectorant for treatment of the upper respiratory tract infection". ${ }^{18}$ Unfortunately, Chinese National monography has not recorded the Elderberry for national medicine in spite of the evidence(Compendium of Materia Medica,1596)suggests that chemicals in elder flower and the berries may reduce swelling in mucous membranes such as the sinuses, and help relieve nasal congestion. Elderberry may have anti-inflammatory, antiviral, and anticancer properties ${ }^{19}$.

\section{SAMBUCUS IN THE WORLD}

There is a folk song that highlights the importance of the elderberry, "Skin, leaf, flower and fruit, each piece is a treasure"19. The medicinal plant is used to relieve stress, various stomach ailments, high cholesterol, congestion, and to fight all strains of the flu. Elderberries additionally promote a healthy complexion and strengthen the body's immune system. The main elderberry species is Sambucus nigra, which is native and common in Europe and the UK. It is found wild along hedgerows, edges of woodlands and on waste ground. Sambucus canadensis, the American elderberry, originates from northern America, and is similar to Sambucus nigra. ${ }^{19}$ Sambucus caerule, the blue elderberry and Sambucus mexicana, are similar species', with the latter originating from warmer climates. The fruit may be blue, bright-blue, or red. ${ }^{19}$

Since the launch of Sambucol in the US in 1995, and achievement of the Vity Awards in 1997, 1998, 1999, numerous products have appeared and the beneficial properties of elderberry are now known worldwide ${ }^{20,21 .}$ Sambucus nigra L. product -Sambucol was shown to be effective in vitro against 10 strains of influenza virus. In a double-blind, placebo-controlled, randomized study, Sambucol reduced the duration of flu symptoms to 3-4 days. ${ }^{22}$. A standardized elderberry extract, (Sambucus nigra), reduced hemagglutination and inhibited replication of human influenza viruses type A/Shandong 9/93 (H3N2), A/Beijing32/92 (H3N2), A /Texas3 6/91 (H1, N1) A, /Singapore6 /85(H1N1) $)^{23}$. On influenza A and B viruses, elderberry extract offers an efficient, safe and cost-effective supplement to the present armamentarium of medications for the prophylaxis and treatment of influenza ${ }^{24}$. The elderberry extract inhibited Human Influenza A (H1N1) infection in vitro with an IC50 value of $252 \pm 34 \mathrm{lg} / \mathrm{mL}$. The Direct Binding Assay established that flavonoids from the elderberry extract bind to H1N1 virions and, when bound, block the ability of the viruses to infect host cells. These flavonoids are the major contributors to the anti-influenza activity of the elderberry extract. The molecular mode-of-action of these flavonoids was determined by demonstrating their direct binding to H1N1 virus particles resulting in the inability of the H1N1 viruses to enter host cells, effectively preventing H1N1 infection in vitro ${ }^{25}$. The action of elderberry (Sambucus nigra) is both direct - suppressing viral entry, affecting the post-infection phase, and viral transmission from cell to cell, and indirect - by modulating the release of cytokines such as IL-6, IL-8, and $\mathrm{TNF}^{26}$.

Elderberry contains flavonoids, which have antioxidant properties and may help to prevent damage to the body's cells. However, very few studies have been done in humans, so researchers have no exact data about the effectiveness of elderberry. Of the several species of elder, Sambucus nigra, the European or black elder, is used the most commonly for medicinal purposes. The dwarf elder (Sambucus ebulus) is to be avoided as it is toxic. Recommendations suggest using a trusted preparation of elder, raw or unripe fruit -as well as the 
leaves, seeds, and rind -contain a chemical related to cyanide, which is poisonous ${ }^{27,28}$.

Elderberry (Sambucus nigra L. subsp. nigra) is a European species with an oceanic, sub-oceanic, cooltemperate and west-Mediterranean range. This species is common in western and central Europe as well as North Africa, Scandinavia and Great Britain. Its distribution range reaches $63 \mathrm{degN}$ latitude in western Norway (with scattered naturalized shrubs up to at least $68 \mathrm{degN}$ ) and approximately $55 \mathrm{degN}$ in Lithuania ${ }^{27,28}$.

The name of Sambuce comes from an ancient Greek wind instrument, in reference to the removal of pith from the twigs to make whistles ${ }^{29}$. There are 26 species recognized inSambuce ${ }^{23}$ and we have found 20 species in the NCBI-National Center for Biotechnology Information advances science and health by providing access to biomedical and genomic information ${ }^{30}$.

The sequence of the 20 elderberry species from NCBI and the known sequences on NCBI were clustered by software MEGA 10.0 (Fig. 1). Our results showed that the 20 elderberry species were classified into 3 main Sambucus group with 5 species in the Pink-Color-Group:S. canadensis in eastern North America; S. javanica in southeastern Asia; S. nigra in Europe and North America; S. palmensis in Canary Islands; S. peruviana in Costa Rica, Panama and northwest South America and 5 species in the Green-Color-Group:S. adnate in Himalaya and eastern Asia; S. australasica in New Guinea, eastern Australia; S. ebulus in central and southern Europe, northwest Africa and southwest Asia; S. wightiana in western Himalayas; S. gaudichaudiana in south eastern Australia and 9 species in the Blue-Color-Group : S. callicarpa in west coast of North America; S. cerulea in western North America;S. melanocarpa in western North America; S. microbotrys in southwest North America; S. pubens in northern North America; S. racemosa in northern Europe, northwest Asia and central North America; $S$. sieboldiana in Japan and Korea; $S$. tigranii in southwest Asia; $S$. williamsii in northeast Asia.

Solo specie is Sambucus australis in South America (Fig.1) and we could not find 6 species from NCBI:Sambucus lanceolata in Madeira Island; Sambucus latipinna in Korea, southeast Siberia;Sambucus orbiculata in western North America; Sambucus sibirica in eastern Asia; Sambucus simpsonii in southeastern United States; Sambucus velutina in southwestern North America. 


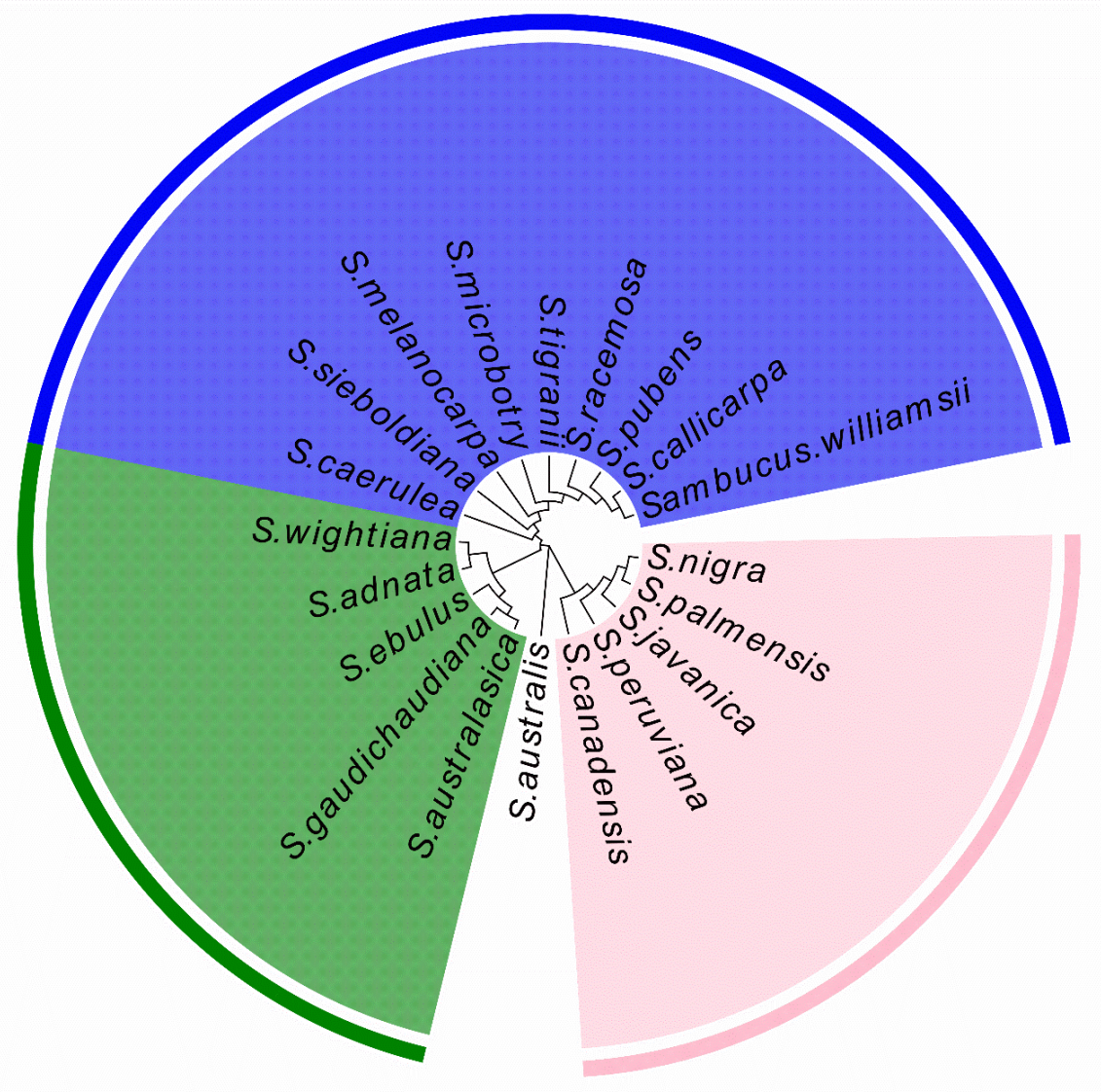

There are 20 speciesof Sambucus in the NCBI
National Center for Biotechnology Information

Fig.1. Dendrogram of Clustering species from NCBI and Phylogenetic tree based on sequences of 20 species from NCBI- The National Center for Biotechnology Information.

\section{SAMBUCUS SPECIES IN CHINA}

There may be 11 species of elderberry in China ${ }^{8.9 .10}$ (and grow from temperate to subtropical regions and tropical mountains. It is not clear when the Sambucus Nigra LinnEuropean elderberry and Sambucus Canadian Linn American elderberry were brought into China (Beijing Shanghai, Shandong and Jiangsu Province).

Pollen morphology is of great significance in taxonomy, phylogeny, and paleobotany. Scanning electron microscopy (SEM) studies on pollen from cultivated fruit trees have been carried out for taxonomic purposes and cultivar identification. A pollen diagnosis for our 3 popular elderberry species investigated, European elderberry (Sambucus Nigra Linn), American elderberry (Sambucus Canadian Linn ) and Chinese Woodyelderberry (Sambucus wiiliamsii) been made through scanning electron microscopy are presented below Fig.2 and Fig. 3: 

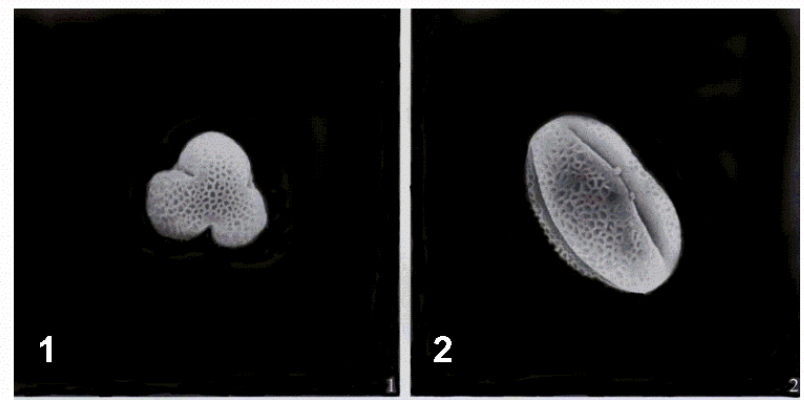

a. European

Elderberry (Sambucus

Nigra Linn) was in

Beijing of China
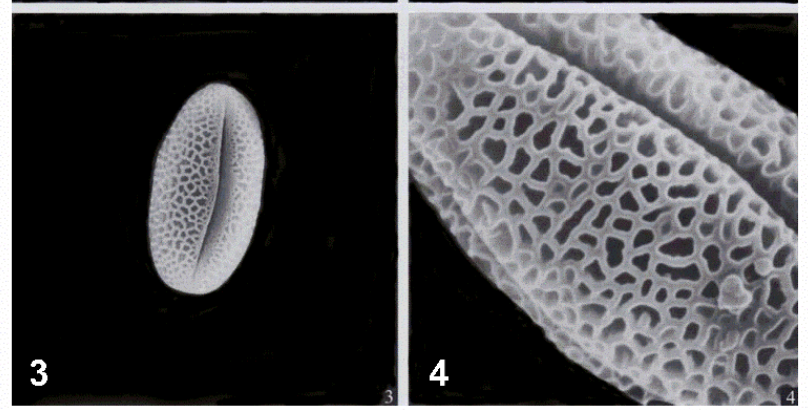

1. Polar view;

2.3. Equatorial view

$\times 1700$;

4.Ornamentation $X$

6000
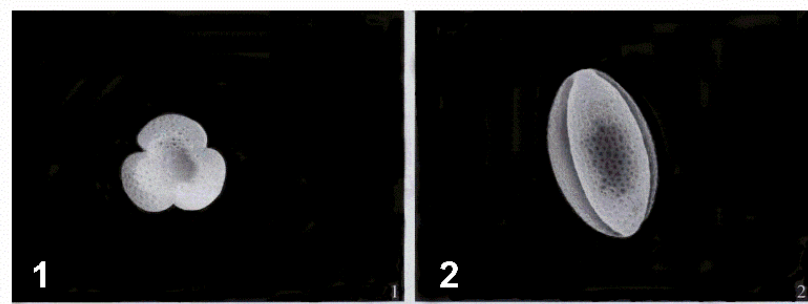

b. Canadian

Elderberry

(Sambucus

Canadensis Linn)

also named American

elderberry was in

Beijing Botany

Garden of China
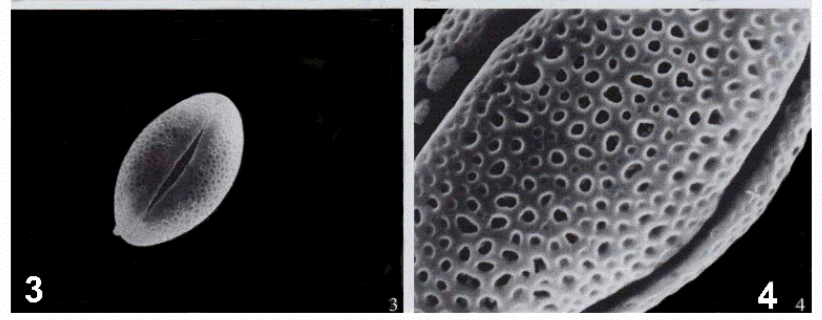

1. Polar view;

2.3. Equatorial view $X$

1700;

4.Ornamentation $x$

6000

Fig.2. a-1. The pollen has a 3-hole groove; a-2. and a-3. The pollen size is about $24 \mathrm{X} 14 \mathrm{um}$, the pollen shape is a long-ball shape with a 3 -sided circular shape on the polar surface; a- 4 . The exine surface has a mesh pattern, which is irregularly shaped, and the side of the mesh backbone grain is occasionally seen.

b-1. The pollen has a 3-hole groove, the polar view with 3 parts is round and the polar region is small and raised, and the hole is not obvious; b-2. and b-3. The equatorial plane is oblong, the pollen size is about $21 \mathrm{X} 12 \mathrm{um}$, the pollen shape is long-balloon. b-4. The exine surface has a mesh pattern, the mesh backbone is wide, and the mesh circle is irregularly rounded, and there are few particles inside the mesh. 

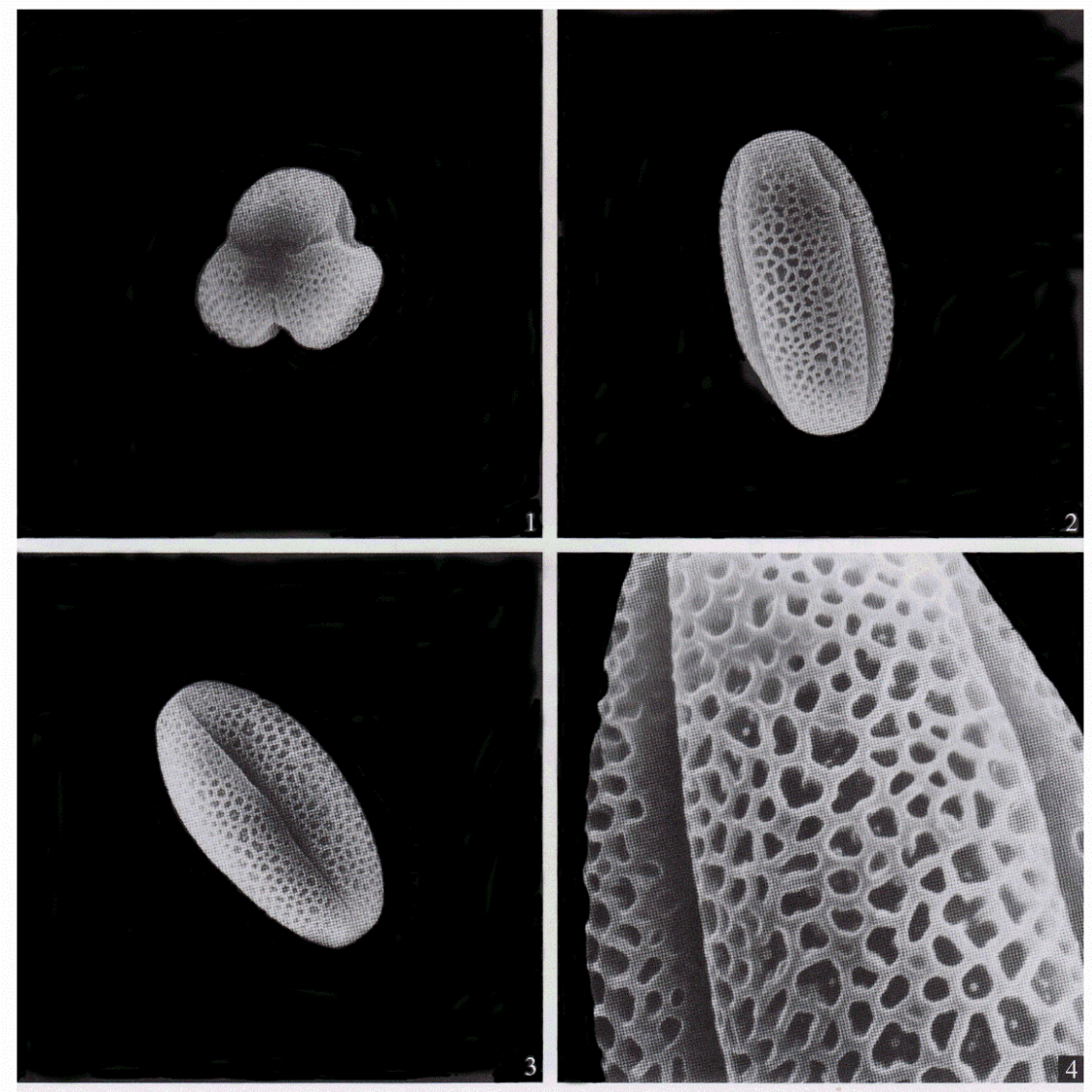

1. Polar view;

2.3. Equatorial view $\times 1700$;

4. Ornamentation $\times 6000$

The Pollen of Chinese Elderberry named Woody-elderberry

(Sambucus williamsii Hance) was in Beijing Xishan, China

Fig. 3. 1. The pollen has a 3 -hole groove and the polar view is 3 -shaped and round; 2 . and 3 . The shape is a long-ball type and pollen size is about (19-17) X (14-16) um. 4. The exine surface has a mesh pattern. The mesh is round (an irregular polygon) and the base particle is occasionally seen on the side of the mesh backbone.

\section{Chinese Woody-elderberry:Sambucus wiiliamsii}

This elderberry is a deciduous shrub or small tree, 5-6m high and the old branches are a reddish-brown color with clear oblong lenticels and a pith of hazel color. Pinnate leaves have one to five pairs, the shape is lateral, small and oval, narrowly elliptic to oblong-lanceolate $5-15 \mathrm{~cm}$ long and $1.2-7 \mathrm{~cm}$ wide. Leaves have a strong smell if rubbed. Flowers and leaves are growing at the same time with a conical cymes $5-11 \mathrm{~cm}$ long and $4-14 \mathrm{~cm}$ wide. With a peduncle, most of the inflorescence branches are at right angles. Fruit is red and rarely blue, violet or black. In the wild, the flowering period is from April to May and the fruit ripening period is from September to October. (Fig5-2.) We have tested the HPLC for Chinese Woody-Elderberry (Sambucus wiiliamsii) with standard and tested materials. Fig 4.

Geographic Distributions: From Wikipedia, the species is recognized in northeast Asian and from Chinese Words Dictionary the species is recognized in Anhui, Fujian, Gansu, Guangdong, Guangxi, Guizhou, Hebei, 
Henan, Heilongjiang, Hubei, Hunan, Liaoning, Jiangsu, Jilin, Shandong, Shanxi, Shaanxi, Sichuan, Yunnan and Zhejiang, The plants are most commonly found under the forest trees, along ditches, among thickets, on valley slopes, in wetlands and among alpine meadows at about 540-1600 meters above sea level.

Medical uses: Whole plant could be used for medicine in curing rheumatism,removing dampness through diuresis, invigorating the circulation of blood, pain relief,treatment of rheumatic arthralgia and myalgia, treatment of lower back pain, treatment of edema, treatment of pruritus, treatment of urticarial, treatment of postpartum ischemia, treatment of traumatic swelling, treatment of bone fractures or the treatment of traumatic hemorrhages.

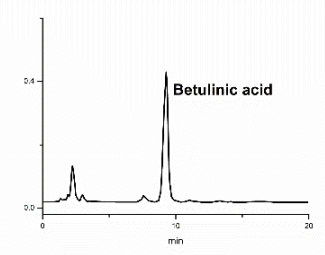

a. Standard Betulinic acid

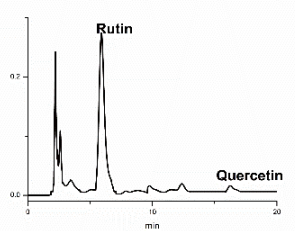

d. Tested Rutin; Quercetin

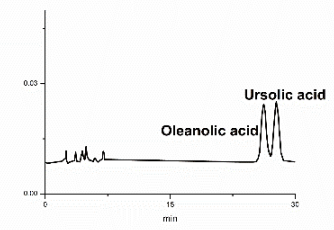

g. Standard Ursolic; Oleanolic acid
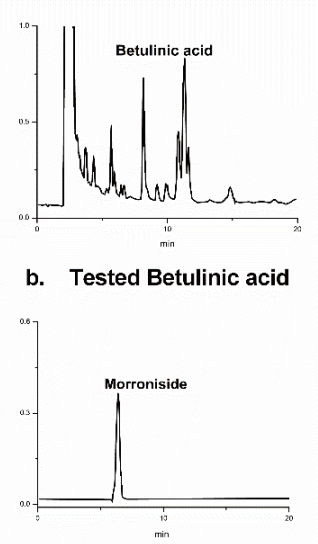

e. Standard Morroniside

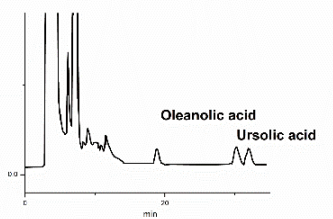

h. Tested Ursolic; Oleanolic acid

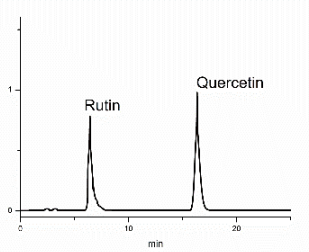

c. Standard Rutin; Quercetin

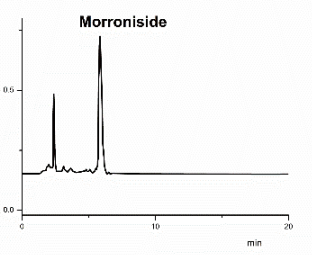

f. Tested Morroniside

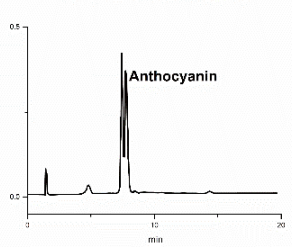

i. Tested Anthocyanin

Fig 4. We have tested the HPLC for Chinese Woody-Elderberry (Sambucus wiiliamsii) with standard and tested materials.

\section{Chinese Blood-red Herb-elderberry: Sambucus adnata}

This elderberry is a high perennial herb or soft-wooded shrub, 1-2 meters high. The roots and rhizomes are red, bursting out red juice when broken. The stems are grass-like and have obvious ribs. The leaves are small with three to five pairs and an oblong, ovate or lanceolate shape 4-15 cm long and 1.5-2.5 cm wide. Flowers are small and white with a strong smell and yellow anthers. Fruit is red with wild flowering time between May-July. The elderberry fruit matures between September and October. Fig 5-1.

Geographic Distributions: From Wikipedia, species is recognized in the Himalaya's and eastern Asia and from Chinese Words Dictionary the species is recognized in Shanxi, Ningxia, Gansu, Qinghai, Sichuan, Guizhou, Yunnan and Tibet. The plants are most commonly found under the forest trees, along ditches, among thickets, on valley slopes, in wetlands and among alpine meadows at about 1600-3600 meters above sea level. Medical uses: It has been used as a traditional medicine to treat bruises, blood stasis, rheumatism, and diuretic problems. ${ }^{10.11}$

\section{Chinese Herb-elderberry: Sambucus chinensis orSambucus javanica.}

This elderberry is a high perennial herb or soft-wooded shrub, 1-2 meters high. The stem has ribs and the pith is white. Leaves are small with two to three pairs and shape is alternate or opposite, narrowly ovate 
$6-13 \mathrm{~cm}$ long and $2-3 \mathrm{~cm}$ wide. New leaves have a hairy surface. Flowers are white, only the base of the joint and anthers are yellow or purple. Fruit is red and wild flowering time is from April to May, ripening between August and September (Fig 5-3 ).

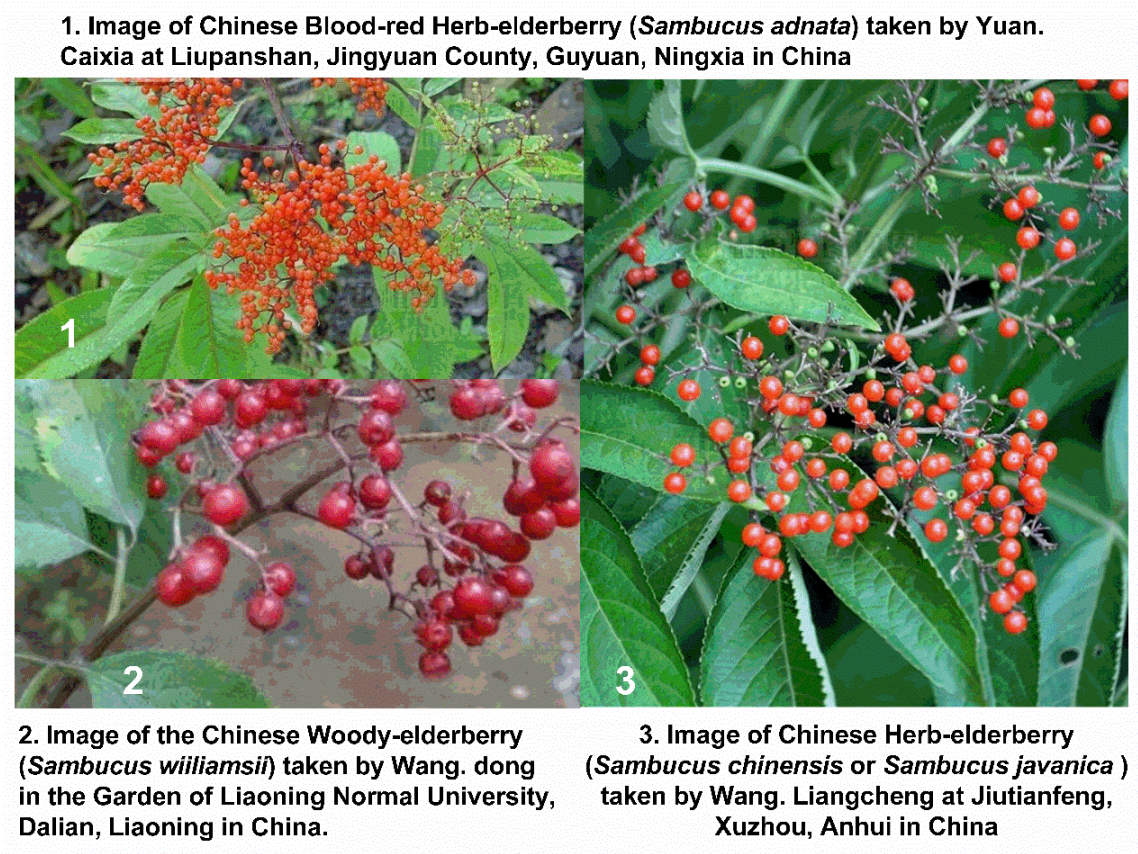

Fig 5 . The Imaging of three Chinese Elderberries: 1. Chinese Blood-red Herb-elderberry (Sambucus adnata ); 2. Chinese Woody-elderberry (Sambucus wiiliamsii ); 3. Chinese Herb-Elderberry (Sambucus chinensis orSambucus javanica) .

Geographic Distributions: From Wikipedia, the species is recognized in southeastern Asia and from Chinese Words Dictionary the species is recognized in Anhui, Fujian, Henan, Hubei, Hunan, Gansu, Guangdong, Guangxi, Guizhou, Shanxi, Jiangsu, Jiangxi, Sichuan, Taiwan, Tibet, Yunnan, Zhejiang and Japan. Medical uses: This species is recorded in old Chinese medical books as an herb to treat bruises, rheumatism, help blood circulation, and it is believed to have detoxification anti-inflammatory effect.

\section{Siberian Woody-elderberry: Sambucus sibirica}

This species is a deciduous shrub, $2-4 \mathrm{~m}$ high, densely branched with reddish brown skin and vertical cracks. There are oval lenticels, with a light brown pith and twigs with a white papilla. The pinnate usually has two pairs of leaflets, and the rachis and petiole have yellow hirsutes. Small leaves are lanceolate $5-14 \mathrm{~cm}$ long and $1.6-5.5 \mathrm{~cm}$ wide. Flowers are light green or yellow with conical cymes. Anthers are ocher yellow and fruit is bright red. Fruit mature period is from July to August.

Geographic Distributions: Xinjiang Fuyun, Fuhai, Siberia and Altai. The plants are most commonly found on stony slopes and beside the stream beds. Medical uses: There are not common uses of this species.

\section{Hairy Woody-elderberry: Sambucus sieboldiana or S. buergeriana.}

This elderberry has new shoots, rachis, pedicels, petioles, and a leaf surface covered by long hair. It is a deciduous shrub or small tree 4-5m high. Small pinnate leaves have two or three pairs, small leaves' main vein and lateral surface contains obvious yellowish-white hair. There is yellow hair on the petiole, rachis and young shoots surface. Fruit is orange-red with two or three seeds. The flowering period is from mid-May to early-June and fruit mature time is July to August. 
Geographic Distributions: Inner-Mongolia, Heilongjiang, Jilin, Liaoning as well as Korea and Japan. The plants are most commonly found on valley slopes, forest margins and desert areas at about 540-1600m above sea level. Medical uses: This species can be used for landscaping trees and various medicinal properties, similar to the Wood Elderberry. New leaves could be consumable and the crushed mixture of shoots and leaves could help in curing injuries of muscles and bones.

\section{Hook-tooth Leaf Woody-elderberry: Sambucus foetidissinia}

This species is a deciduous shrub 4-5m high, with an odd number pinnate with five to seven pairs. The leaf shape is oval or slightly oblong, $6-9 \mathrm{~cm}$ long and $1.5-4 \mathrm{~cm}$ wide. The leaves have a strong smell and thick, sharp, serrated teeth. The teeth bend inward like hooks. The fruit is red and flowering time is from May to June, fruit mature time is August-September.

Geographic Distributions: Inner-Mongolia only, there is a chance it could be found in Huabei, but no formal record exists. Medical uses: The species is used in landscaping trees and for various medicinal properties.

\section{North-Korean Woody-elderberry: Sambucus coreaana}

This elderberry is a deciduous shrub $5 \mathrm{~m}$ high, with an odd number pinnate with three to five pairs. The leaf shape is lanceolate, $1.5-5 \mathrm{~cm}$ long and $0.7-2 \mathrm{~cm}$ wide. The flower is conical inflorescence and light green, the anther is yellow. The fruit is red with three seeds flowering from May to June and maturing in August.

Geographic Distributions: Inner-Mongolia, Heilongjiang, Jilin, Liaoning as well as North-Korea and east of Russia. The plants are most commonly found on the mountain slope and forest margins. Medical uses: The shoots and leaves have medicinal value. The unique seeds contain $18.8 \%$ oil which can be used to make soaps and candles. The species may be used in landscaping trees.

\section{Latifolia Woody-elderberry: Sambucus latipinna}

This elderberry is a deciduous shrub, about $3 \mathrm{~m}$ high, with an odd number of pinnate, opposite with three to five pairs. The leaf shape is oval or oblong, $4-8 \mathrm{~cm}$ long and $2-3.5 \mathrm{~cm}$ wide. It called latifolia as the leaflet is $2-3.5 \mathrm{~cm}$ wide. The flower is conical inflorescence and yellow-green in colour with yellow anthers. The fruit is orange-red flowering in May and maturing in August and September.

Geographic Distributions: Inner-Mongolia, Jilin, Liaoning as well as North-Korea. Shrubs are most commonly found on the mountain slopes, especially along stream beds and in meadowland. Medical uses: There are no common uses of this species.

\section{Northern-east Woody-elderberry: Sambucus mandshurica}

This elderberry is a deciduous shrub about $6 \mathrm{~m}$ high. The branches grow upright with a reddish grey skin color. There is an odd number of pinnate, opposite with five to seven pairs. The leaf shape is oblong; $2-6 \mathrm{~cm}$ long and $1-2 \mathrm{~cm}$ wide. The flower is large conical inflorescence and yellow-green. The anther is yellow and the fruit is red. The flowering period is between May and June and matures in August to September.

Geographic Distributions: Heilongjiang, Jilin, Liaoning, North-Korea, Mongolia, far-east and east-Siberia in Russia. Shrubs are most commonly found on the mountain slopes, especially along stream beds, at bush forest margins, or in low scrub and meadowlands. Medical uses: Shoots and leaves of this species have medicinal value. They are proven to help recover injuries of tendons and muscles. It may also be used in landscaping trees.

\section{CONCLUSION}

It is accepted that there are 11 species of elderberry in China. There is not the evidence about when the Sambucus nigra species of elderberry was brought to China (Shanghai, Shandong and Jiangsu Province). In southwest China, where the climate is mildly warm (COVID-19 outbreak zone), there are 2 species of elderberries; one, Sambucus adnata, is termed the "blood-red herb-elderberry" by local residents as the 
roots, rhizomes, and branches exude red-juice when broken. The second, named S. javanica or S. chinensis, is commonly called the "herb-elderberry".

In northeast China where the climate is cold, there are 7 species of elderberry, however, most scientists recognize only 2 main species: Sambucus. williamsii, commonly called the "woody-elderberry", and Sambucus sibirica, commonly called the "Siberian woody-elderberry". The other 5 species of elderberry in northerneast of China are not commonly known to scientists. Sambucus sieboldiana is significantly different from S. williamsii, and is commonly called the "hairy-woody-elderberry". The remaining species are S. foetidissima, the "hook-tooth-leaf woody-elderberry", S. coreana, the "North-Korean woody elderberry" originating in North-Korea with unique seeds containing $18.8 \%$ oil, S. latipinna, the "broad-leaf woody-elderberry", and S. manshurica, the "northeast woody-elderberry". The leaves and shoots of the S. manshurica have been used as traditional Chinese medicines to treat human bone fractures.

People have begun to recognize the immense health benefit of elderberry. As a researcher, it is incredibly exciting to be a part of something that has such a positive impact on the world. American elderberry and European elderberry have significantly inability to the flu viruses and cold viruses, Forward the history of antimalarials, we believe that one of 9 Chinese elderberries should be inhibition of the Novel Coronavirus (COVID-19).

\section{REFERENCE}

Overview of 2019 novel coronavirus (2019-nCoV),

https://bestpractice.bmj.com/topics/engb/3000165? q=Coronavirus,\%202019\%20novel\&cc=suggested

1. Novel Coronavirus(2019-nCoV) Situation Report - 22,https://www.who.int/docs/defaultsource/coronaviruse/situation-reports/20200211-sitrep-22-ncov.pdf?sfvrsn=fb6d49b1_2

2. Layne, S. P., Monto, A. S., \& Taubenberger, J. K. (2009). Pandemic influenza: an inconvenient mutation. Science (New York, N.Y.), 323(5921), 1560-1561.https://doi.org/10.1126/science.323.5921.1560

3. WHOhttps://www.who.int/emergencies/diseases/novel-coronavirus-2019/advice-for-public/mythbusters

4. History of antimalarials.https://www.mmv.org/malaria-medicines/history-antimalarials

5. Atropine.https://en.wikipedia.org/wiki/Atropine.

6. Maria A. Neag,1 Andrei Mocan,2,* Javier Echeverría,3 Raluca M. Pop,1 Corina I. Bocsan,1 Gianina Crişan,2 and Anca D. Buzoianu1(2018).Berberine: Botanical Occurrence, Traditional Uses, Extraction Methods, and Relevance in Cardiovascular, Metabolic, Hepatic, and Renal Disorders. Front Pharmacol. 2018; 9: 557.Front Pharmacol. 2018; 9: 557.

7. Rauwolfia Dorlands Medical Dictionary. Merck Source. 2002.

8. Goodman and Gilman's Pharmacological Basis of Therapeutics, q.v. "Muscarinic receptor antagonists - History", p. 163 of the 2001 edition.

9. Bernard C (1856). "Analyse physiologie des propriétés des actions de curare et de la nicotine sure systèmes musculaire et nerveux au moyen du curare". Compt. Rend. 43: 305-319.

10. "BSBI List 2007". Botanical Society of Britain and Ireland. Archived from the original (xls) on 23 October 2014. Retrieved 17 October 2014.

11. Bell, A. \& Bachman, S. (2011). Ephedra sinica. The IUCN Red List of Threatened Species 2011: e.T201702A9168958. doi:10.2305/IUCN.UK.2011-2.RLTS.T201702A9168958.en. Downloaded on 05 September 2018.

12. "World Checklist of Selected Plant Families: Royal Botanic Gardens, Kew". apps.kew.org. Retrieved 2016-07-07

13. Taxol@ (NSC 125973)". National Cancer Institute. Archived from the original on 5 September 2015. Retrieved 14 February 2016. Wayback machine

14. TR Govindachari and N. Viswnathan, Phytochemistry,11(12), 3529-31 (1972).

15. Efferth T, Fu YJ, Zu YG, Schwarz G, Konkimalla VS, Wink M (2007). "Molecular target-guided tumor therapy with natural products derived from traditional Chinese medicine". Current Medicinal 
Chemistry. 14 (19): 2024-32. doi:10.2174/092986707781368441.

16. National Cancer Institute: Definition of Maytansine; https://www.cancer.gov/publications/dictionaries/cancerdrug/def/maytansine? redirect=true

17. WHO Monographs on Selected Medicinal Plants - Volume 2.

https://apps.who.int/medicinedocs/en/d/Js4927e/26.html

1. Compendium of Materia Medica,1596 also known as Bencao Gangmu, Chinese words.

2. Flora of China Chinese words, http://frps.eflora.cn/

3. Flora of Heilongjiang Chinese words,http://v2.cvh.org.cn/difangzhi/heilongjiang/list.asp

4. Flora of Inner-Mongolia Chinese words,http://v2.cvh.org.cn/difangzhi/neimenggu/list.asp

5. Sambucus - Wikipedia, the free encyclopedia,http://en.wikipedia.org/wiki/Sambucus"

6. Sambucus - The Plant List". www.theplantlist.org. Retrieved 2017-10-17.

7. Barak, V., et al. (2001). The effect of Sambucol, a black elderberry-based, natural product, on the production of human cytokines: I. Inflammatory cytokines. European Cytokine Network, 12(2), 290-296.

8. Zakay-Rones $\mathrm{Z}$ et al. Inhibition of several strains of influenza virus in vitro and reduction of symptoms by an elderberry extract (Sambucus Nigra L.) during an outbreak of Influenza B Panama. J Altern Complement Med. 1995;1(4):361-9.

9. Zakay-Rones Z, et al. Randomized study of the efficacy and safety of oral elderberry extract in the treatment of Influenza A and B virus infections." J Int Med Res. 2004;32(2):132-40.

10. Roschek B Jr. et al. Elderberry flavonoids bind to and prevent H1N1 infection in vitro. Phytochemistry. 2009;70(10):1255-61. doi: 10.1016/j.phytochem.2009.06.003

11. Golnoosh Torabian et al. 2019, Anti-influenza activity of elderberry (Sambucus nigra). Journal of Functional Foods 54 (2019) 353-360

12. Niering, William A.; Olmstead, Nancy C. (1985) [1979]. The Audubon Society Field Guide to North American Wildflowers, Eastern Region. Knopf. p. 448. ISBN 0-394-50432-1.

13. NCBI- The National Center for Biotechnology Information.https://www.ncbi.nlm.nih.gov/

14. S. Chrubasik. Ist International Symposium on Elderberry, Acta Hort. 1061, ISHS 2015. A Review of Pharmacological Effects and Clinical Efficacy of Fruit Products and Functional Foods from Elderberry (Sambucus spp.) as Compared with Chokeberry (Aronia melanocarpa)

15. I. Salamon and D. Grulova. Proc. Ist International Symposium on Elderberry, Acta Hort. 1061, ISHS 2015. Elderberry (Sambucus nigra): from Natural Medicine in Ancient Times to Protection against Witches in the Middle Ages - a Brief Historical Overview

16. W.L. Applequist. Ist International Symposium on Elderberry, Acta Hort. 1061, ISHS 2015.A Brief Review of Recent Controversies in the Taxonomy and Nomenclature of Sambucus nigra sensu lato

\section{ACKNOWLEDGEMENT}

\section{Declaration for author contribution statement}

FrankQiang Fu : Conceived and designed the experiments; Performed the experiments; Analyzed and interpreted the data; wrote the paper.

Mingshu Xu : Conceived and designed the experiments; Performed the experiments; Analyzed and interpreted the data; Contributed reagents, materials, Analysis tools or data.

Weidong Li: He is the supervisor of the Ph.D. at Beijing University of Chinese Medicine.

\section{Funding statement}

This work was supported by New Zealand Ministry of Business, Innovation and Employment (Grant number 202001130213) and Horticulture Institute of New Zealand.

Dr. Mingshu Xu's Research Fellow Reward funded by the Horticulture Institute of New Zealand (Grant 
number 202001130213).

\section{Declaration of interest}

The authors declare that they have no competing interests. 